\title{
The role of inflammation in childhood asthma
}

\author{
Frederique Chedevergne, Muriel Le Bourgeois, Jacques de Blic, Pierre Scheinmann
}

\begin{abstract}
The role of inflammation in adult asthma is well known, involving a cascade of immunological stimulation in which mast cells and eosinophils play pivotal roles. However, the assessment of airway inflammation in children is more difficult as the invasive methods used in adults cannot ethically be used for this purpose alone. Nevertheless, limited data from studies using invasive methodology, and studies using novel non-invasive techniques such as sputum induction and nitrous oxide exhalation, are improving knowledge. The immunopathology in childhood asthma appears to mirror that in adult sufferers. The inflammatory processes are evident at an early age in wheezing infants who later develop asthma, and there are different "wheezing phenotypes" in children with atopic asthma or viral associated wheeze. The mechanisms underlying childhood asthma are dependent not only on increased numbers of inflammatory cells in the airways, but also increased activation of these cells. In vitro data have shown that corticosteroids can inhibit the secretion of proinflammatory compounds from alveolar macrophages, suggesting a potential important role for these agents in halting the development of asthma. Techniques for measuring inflammation in infants need to be refined, in order to provide increased knowledge and accurate monitoring of the disease. It is hoped that this will enable the development of early interventions to minimise the impact of asthma in infants who are identified as being susceptible.

(Arch Dis Child 2000;82(Suppl II):ii6-ii9)
\end{abstract}

Keywords: asthma; immunopathology; prognostic indicators; inflammatory markers

Airway inflammation is an important feature in the development and progression of many respiratory disorders. It plays a central role in the pathogenesis of asthma in adults, ${ }^{1}$ but the role of inflammation in paediatric asthma is less clear. This is largely because invasive methods of monitoring airway inflammation, such as flexible bronchoscopy and bronchoalveolar lavage (BAL), can only be carried out in children when there is a clear clinical indication to do so. It would not be ethical to perform such procedures purely to assess concentrations of inflammatory cells, and peripheral measurements of inflammation from blood or urine samples are less direct and may not be predictive of acute changes. ${ }^{2}$
Reliable assessment of airway inflammation is important because it provides an insight into the immunopathology of asthma, and also may lead to a more definitive assessment of the efficacy of asthma medication than that provided by lung function measurements. Recent studies using both invasive techniques (when justified by clinical circumstances) and newer, noninvasive measurements have provided increasing evidence of the role of inflammation in the pathology of childhood asthma. These studies and their significance are reviewed in this paper.

Data from BAL secretions of paediatric patients with asthma

An early analysis of BAL fluids from children aged 6-16 years with chronic asthma revealed that eosinophil concentrations were correlated with the degree of bronchial hyperresponsiveness (BHR). ${ }^{3}$ In a later study, BHR was also found to correlate with increased concentrations of mast cells. ${ }^{4}$ These results imply that mast cells and eosinophils play a similar role in paediatric asthma to that in adult asthma.

Using a non-bronchoscopic BAL procedure, Stevenson et al showed that eosinophils and mast cell concentrations are significantly increased in children (less than 5 years old) with atopic asthma, in comparison with children with viral induced wheezing (fig 1$).^{5}$ Study participants were assessed during relatively asymptomatic periods, implying that atopic asthma is associated with ongoing inflammation. These results also suggest that there are different underlying mechanisms involved in atopic asthma and viral induced wheezing. Unfortunately, the study did not indicate the proportions of children aged under 2 or 3 years, making it impossible to draw conclusions for infants.

More recently, the BAL cell profiles from 73 wheezing infants aged under 3 years were compared with those of 17 non-wheezing controls. ${ }^{6}$ The latter had various pulmonary pathologies (justifying the invasive BAL procedure), but no bronchial inflammation. Surprisingly, no significant differences were observed between concentrations of eosinophils and macrophages in the two groups, although a small but statistically significant increase in neutrophils and a small decrease in lymphocytes was found in wheezers (fig 2). Thus, proinflammatory cells can be present in both wheezing and non-wheezing young infants with pulmonary pathologies. This suggests that mechanisms other than increased concentrations of eosinophils and mast cells are involved in the pathophysiology of persistent wheezing.

Researchers therefore proposed that differences in the activation of proinflammatory cells 

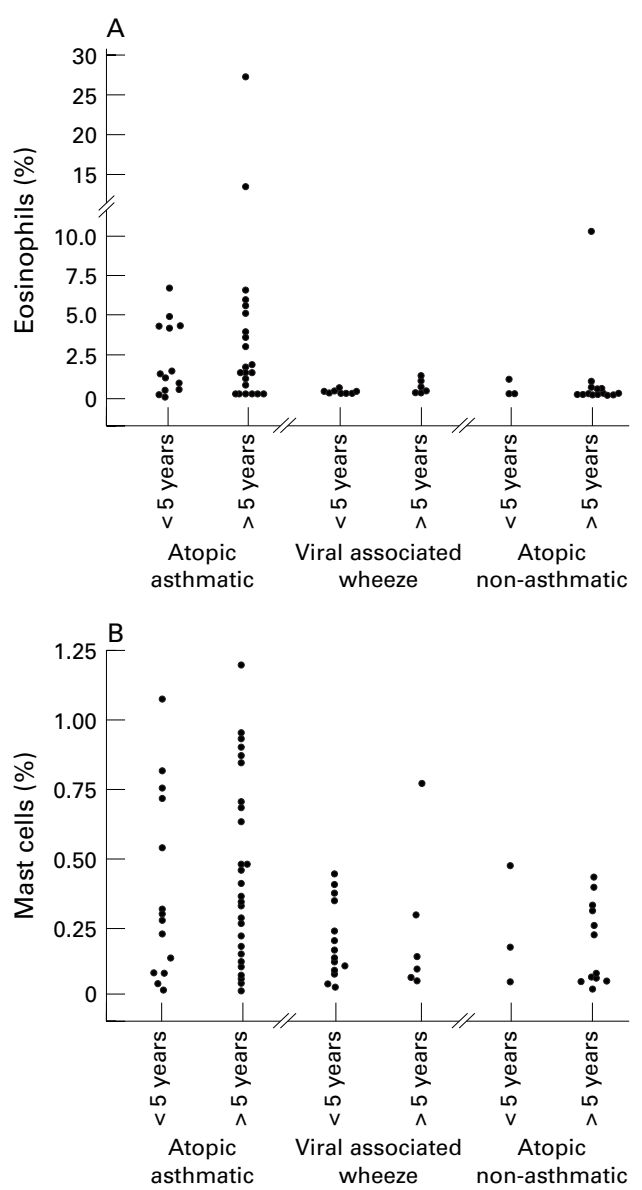

Figure 1 Eosinophil $(A)$ and mast cell (B) percentages in lavage fluid from children with atopic asthma $(n=52)$, viral associated wheeze $(n=20)$, and atopy without respiratory disease $(n=23)$. Reproduced with permission. ${ }^{5}$

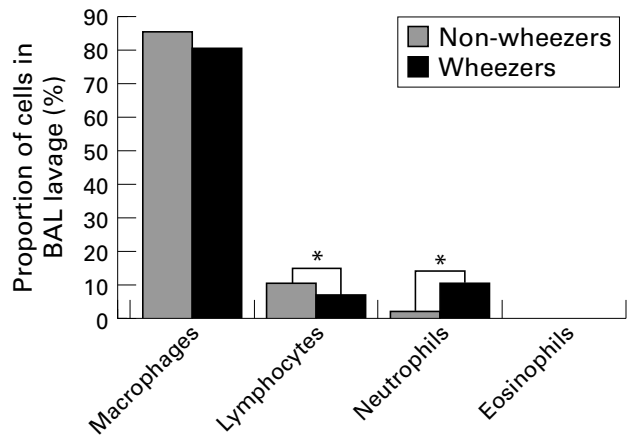

Figure $2 B A L$ cell profiles in non-wheezing and wheezing infants under 3 years of age. ${ }^{\star} p<0.01$ (data from Le Bourgeois et $a l^{6}$ ).

may determine whether infants will proceed to develop childhood asthma.

\section{Inflammatory mechanisms in adult asthma}

The immunological processes involved in adult asthma have been well characterised. ${ }^{1}$ The principal inflammatory agents are activated eosinophils and mast cells, which are instrumental in causing structural changes to the epithelium. Initially, degradation of the epithelium occurs and junctional adhesion structures are weakened. In response to this, collagen is deposited beneath the basement membrane, resulting in increased thickness. There is an accompanying increase in airway smooth muscle and new blood vessels are generated. Mast cells initiate an early response to allergens, by degranulating and releasing stored inflammatory mediators. ${ }^{?}$

Antigen presenting cells (APCs) facilitate the activation of $\mathrm{T}$ lymphocytes by engulfing foreign allergenic particles and presenting the processed fragments on their surface. This occurs about 8-24 hours after allergen exposure (late response). ${ }^{7}$ Activated (CD4+) T cells of the $\mathrm{T}_{\mathrm{h}} 2$ phenotype secrete cytokines including interleukin 4 (IL-4), IL-5, IL-13, and tumour necrosis factor $\alpha(\mathrm{TNF}-\alpha)$, while $\mathrm{T}_{\mathrm{h}} 1$ cells secrete IL-2 and interferon $\gamma$ (IFN- $\gamma$ ) (the $\mathrm{T}_{\mathrm{h}} 2$ response predominates in asthma). These cytokines exert a number of effects, including:

- Promotion of the growth and differentiation of inflammatory cells (including eosinophils and mast cells), their activation, and their localisation in airways

- The switching of IgM+ B cells to IgE producing cells; IgE is produced in response to allergic stimulus in atopy and is associated with asthma

- Stimulation of epithelial cells to produce chemokines, metalloproteases, nitric oxide (NO), and adhesion molecules; together, these agents encourage the attraction and binding of eosinophils and $\mathrm{T}$ cells to the epithelium and increase squamous degradation.

All of these inflammatory processes and structural changes underlie BHR.

\section{Cell activation studies in children}

Epidemiological data suggest an association between recurrent bronchiolitis in children younger than 3 years of age and a diagnosis of asthma later in life. ${ }^{8}$ A study was therefore carried out to compare macrophages obtained from BAL samples from infants with recurrent bronchiolitis with those from non-wheezing controls. ${ }^{9}$ Alveolar macrophages from wheezy infants were found to have a decreased sensitivity to the stimulating effect of salbutamol, prostaglandin $\mathrm{E}_{2}\left(\mathrm{PGE}_{2}\right)$, and forskolin than controls (fig 3 ). This suggests that refractoriness to adenyl cyclase stimulation could be one of the precipitating events in the development of asthma.

Azevedo et al compared arachidonic acid metabolism in alveolar macrophages from wheezy versus non-wheezy infants. ${ }^{10}$ Spontaneous release of the proinflammatory eicosanoids thromboxane $\mathrm{A}_{2}$ and leukotriene $\mathrm{B}_{4}$ (both of which are products of arachidonic acid metabolism) was substantially increased in cells from wheezy subjects compared with controls, by factors of 11.0 and 7.2 , respectively. Thromboxane $\mathrm{A}_{2}$ release from macrophages was also 5.8 times higher among wheezy infants than controls, when the cells were stimulated with the calcium ionophore A23187. These results were later reinforced when the release of TNF- $\alpha$ was found to be significantly increased by a factor of 5.6 in alveolar macrophages from infants with severe 


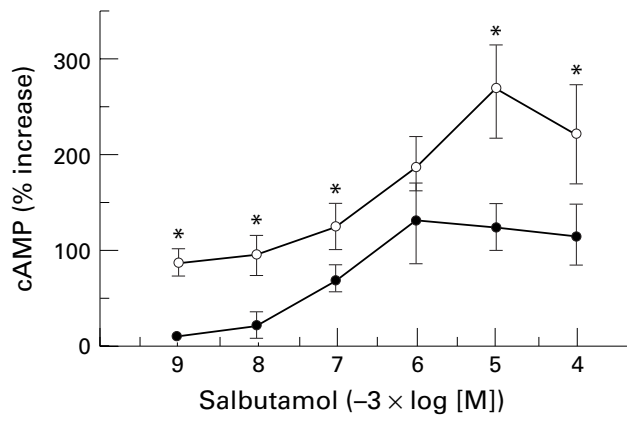

Figure 3 Effect of salbutamol on the intracellular cAMP concentrations of alveolar macrophages from infants with recurrent bronchiolitis (closed circles) and non-wheezing control subjects (open circles). ${ }^{\star} p<0.05$. Reproduced with permission. $^{9}$

recurrent wheezing, compared to controls. ${ }^{11}$ Increased TNF- $\alpha$ secretion has also been described in asthmatic adults. ${ }^{12}$

Interestingly, the studies by Azevedo et al also showed that therapeutic concentrations of dexamethasone inhibited the release of several proinflammatory mediators. At a concentration of $1 \mu \mathrm{M}$, the corticosteroid inhibited thromboxane $\mathrm{A}_{2}$ release by alveolar macrophages by $70 \% .{ }^{10}$ In this study, dexamethasone also inhibited spontaneous release of leukotriene $\mathrm{B}_{4}$, but had no statistically significant effect on the release of this eicosanoid by stimulated macrophages. This indicated that dexamethasone does not, as previously thought, act just by inhibiting the activity of phospholipase $\mathrm{A}_{2}$. Its activity is more complex, involving reductions in the activity of numerous enzymes, cytokines, and adhesion molecules through transcriptional interference. ${ }^{7}$ The later study by the same group showed that dexamethasone $(1 \mu \mathrm{M})$ reduced the release of $\mathrm{TNF}-\alpha$ from activated macrophages of both wheezy and non-wheezy infants by $48 \%{ }^{11}$ Reductions of $35-50 \%$ were also observed in the release of thromboxane $B_{2}$ and prostaglandin $\mathrm{E}_{2}$, confirming the inhibitory effects of dexamethasone on the release of cyclooxygenase metabolites.

Taken together, these studies show that in infants with recurrent wheezing episodes, alveolar macrophages are stimulated to release proinflammatory mediators. This is consistent with the findings of Warner et al, who recently reported an association between asthma symptoms and combined increases in BAL concentrations of soluble intercellular adhesion molecule 1 (sICAM-1) and eosinophil cationic protein (ECP). ${ }^{13}$ The same group also performed biopsies in children aged 1-11 years who were being investigated for respiratory symptoms. At follow up after two to six years, increases in the concentrations of activated eosinophils in the lamina propria and in the thickness of the subepithelial lamina reticularis were seen among those children who had developed asthma, compared with those who did not. This raises the question of whether the immunopathology of asthma becomes established before symptoms appear. In addition, since the BAL procedures were carried out during asymptomatic periods, the results of Azevedo et al indicate that inflammatory stimulation is an ongoing event in infants with recurrent wheeze. This is similar to results described for adults with asthma and suggests a link at the cellular level between recurrent wheezing in infancy and asthma in adults. The inhibitory effects observed with dexamethasone support the therapeutic use of corticosteroids, particularly via inhalation, in infants with severe recurrent wheezing.

\section{Sputum analysis for monitoring airway} inflammation in children

Analysis of saline induced sputum has the potential to be a useful tool in monitoring airway inflammation in children. A major benefit of this technique is that it is non-invasive, and therefore is not subject to the same ethical issues as BAL.

During the 1990 s, several studies using sputum analysis revealed differences between asthmatic children and controls as well as investigating intrasubject differences between symptomatic and asymptomatic periods.

Pioneering work in this area was carried out by Pin et al. In 1993, they showed that eosinophil concentrations in sputum from asymptomatic asthmatic children aged 11-16 years were similar to those of controls while concentrations in symptomatic children were increased. ${ }^{14}$

Twaddell et al examined sputum cell counts in children with acute exacerbations of asthma and found a large cellular infiltrate during acute asthma $\left(34 \times 10^{6}\right.$ cells $\left./ \mathrm{ml}\right)$, comprising many cell types including eosinophils, neutrophils, and mast cells. ${ }^{15}$ When the same subjects were examined 14 days later, on resolution of the exacerbation, a significant fall in the cell count was recorded $\left(1.9 \times 10^{6}\right.$ cells $/ \mathrm{ml}$; $p \leqslant 0.04)$. Another study found that lung function, measured by forced expiratory volume in one second $\left(\mathrm{FEV}_{1}\right)$, decreased with increasing concentrations of sputum eosinophils. ${ }^{16}$ In addition, an epidemiological study performed in 170 children aged 8-14 years found that increased concentrations of sputum eosinophils were correlated with BHR and asthma symptoms. ${ }^{17}$ Among those children with BHR, the probability of having high concentrations of sputum eosinophils was 4.36 times greater than that for subjects without $\mathrm{BHR}$, the equivalent odds ratio for eosinophilia being 2.25 for children with asthma symptoms. BHR was also associated with increased numbers of mast cells (odds ratio of 7.46).

All these findings reinforce the hypothesis that inflammation is present in childhood asthma, and show that this can be monitored by sputum analysis. ${ }^{18}$ However, the technique is limited to children aged over 7 years, as it is very difficult to induce sputum in younger infants. ${ }^{17}$

\section{Nitric oxide}

Recent studies have shown that nitrous oxide (NO) seems to play an important role in asthma and its pathogenesis. ${ }^{19}$ In 1997, Baraldi et al showed that children with acute asthma (mean age 9.3 years, $n=16$ ) exhaled increased concentrations of $\mathrm{NO}$ in comparison with 16 


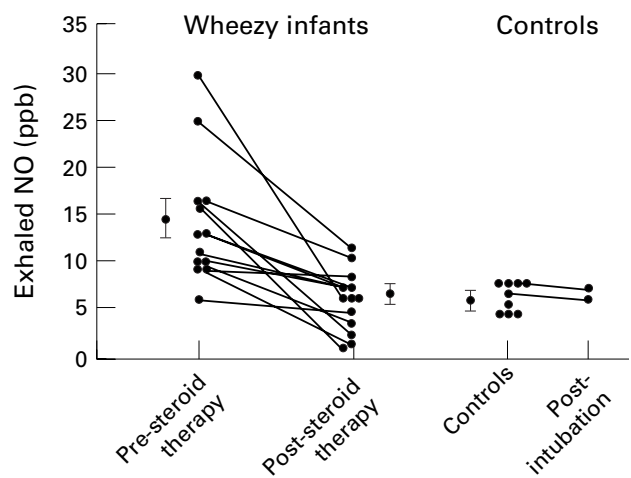

Figure 4 Exhaled NO concentrations in 13 infants with recurrent wheeze before and after 5 days of treatment with oral prednisone, and 9 controls in two of whom NO was measured immediately before and after tracheal intubation for elective surgery. Group means (plus or minus SEM) and individuals are shown. Reproduced with permission. ${ }^{22}$

healthy controls of the same age (31.3 $v 5.4$ parts per billion, ppb). ${ }^{20}$ Prednisone therapy ( 1 $\mathrm{mg} / \mathrm{kg} /$ day for five days) reduced the NO level in asthmatic children to $16.5 \mathrm{ppb}$, significantly below that recorded before corticosteroid therapy, but the level remained significantly higher than that in the controls $(\mathrm{p}<0.001$ for both differences). Recently, exhaled NO concentrations were found by another group to be increased among asthmatic children with a mean age of 11.5 years. ${ }^{21}$

Baraldi et al subsequently studied $\mathrm{NO}$ in infants, comparing individuals with either recurrent wheeze (mean age 20 months) or first time viral wheeze (mean age 11 months) with healthy controls (mean age 17 months). ${ }^{22}$ Significantly higher NO concentrations were found in the group with recurrent wheeze before prednisone therapy compared with controls (14.1 $v 5.6 \mathrm{ppb}, \mathrm{p}<0.001$; fig 4 ). In contrast, mean exhaled NO from infants with first time wheeze $(8.3 \mathrm{ppb})$ was not significantly different from controls. Again, five days of prednisone therapy effectively reduced $\mathrm{NO}$ concentrations in infants with recurrent wheeze, to a mean of $5.9 \mathrm{ppb}$.

The data from NO studies are consistent with the concept that inflammation is present at an early stage in infants with troublesome symptoms, and that measurement of exhaled NO has the potential to distinguish different "wheezing phenotypes". However, further investigations are required to standardise the methodology used in these studies.

\section{Conclusions}

The studies reviewed here support the viewpoint that the immunopathology of paediatric asthma is similar, if not identical, to adult asthma. Airway inflammation may occur in children before the manifestation of symptoms of asthma, and both genetic and environmental factors may be involved. Inhaled corticosteroids, through their ability to inhibit several key inflammatory processes, may have an increasing role to play in the treatment of infants with severe recurrent wheezing. It is now important to identify and confirm an effective test that will reveal both a predisposition to asthma and its severity in patients. Such knowledge should then assist the search for ways to reduce, or even prevent, the natural progression towards the disease in susceptible infants.

\section{Addendum}

Since submission of this paper, M Ennis et al (Ennis M, Turner $\mathrm{G}$, Schlock BC, et al. Inflammatory mediators in bronchoalveolar lavage samples from children with and without asthma. Clin Exp Allergy 1999;29:362-66.) have confirmed that eosinophils and mast cells are activated in children with a history in recurrent wheeze. BAL histamine and ECP were higher in atopics than in children with viral associated wheeze (non-atopics)

1 Holgate ST. The inflammation-repair cycle in asthma: the pivotal role of the airway epithelium. Clin Exp Allergy 1998;28:97-103.

2 Scheinmann P, Pedersen S, Warner JO, De Blic J. Methods for assessment of airways inflammation: paediatrics. Eur Respir F 1996;11:S53-8.

3 Ferguson AC, Wong FWM. Bronchial hyperresponsiveness in asthmatic children. Correlation with macrophages and in asthmatic children. Correlation with macrophages and

4 Ferguson AC, Whitelaw M, Brown H. Correlation of bronchial eosinophil and mast cell activation with bronchial hyperresponsiveness in children with asthma. F Allergy Clin Immunol 1992;90:609-13.

5 Stevenson EC, Turner G, Heaney LG, et al. Bronchoalveolar lavage findings suggest two different forms of childhood asthma. Clin Exp Allergy 1997;29:1027-35.

6 Le Bourgeois M, Goncalves M, Le Clainche L, et al. Bronchoalveolar cells in wheezy children under 3 years. Eur Respir F 1999;14(suppl 30): 171-2.

7 McConnell W, Howarth P. The airway anti-inflammatory effects of fluticasone propionate. Reviews in Contemporary Pharmacotherapy 1998;9:523-33.

8 McConnochie KM, Roghmann KJ. Bronchiolitis as a possible cause of wheezing in childhood: new evidence. Pediatrics 1984;74:1-10.

9 Galoppin L, de Blic J, Azevedo I, Scheinmann P, Vargaftig $B B$, Bachelet M. Nonspecific refractoriness to adenylyl cyclase stimulation in alveolar macrophages from infants with recurrent bronchiolitis. F Allergy Clin Immunol 1994;93:885-90.

10 Azevedo I, de Blic J, Scheinmann P, Vargaftig BB, Bachelet $M$. Enhanced arachidonic acid metabolism in alveolar macrophages from wheezy infants. Am $\mathcal{F}$ Respir Crit Care Med 1995;152:1208-14

11 Azevedo I, de Blic J, Dumarey CH, Scheinmann P, Vargaftig $\mathrm{BB}, \mathrm{Bachelet} \mathrm{M}$. Increased spontaneous release of tumour necrosis factor-a by alveolar macrophages from wheezy infants. Eur Respir F 1997;10:1767-73.

12 Hallsworth MP, Soh CP, Lane SJ, Arm JP, Lee TH. Selective enhancement of GM-CSF, TNF-alpha, IL-1 beta and IL-8 production by monocytes and macrophages of and IL-8 production by monocytes and macroph

13 Warner JO, Marquet C, Rao R, Roche WR, Pohunek P. Inflammatory mechanisms in childhood asthma. Clin Exp Allergy 1998;28:71-5.

14 Pin I, Radford S, Kolendowicz R, et al. Airway inflammation in symptomatic and asymptomatic children with methacholine hyperresponsiveness. Eur Respir F 1993;6:1249-56.

5 Twaddell SH, Gibson PG, Carty K, Woolley KL, Henry RL. Assessment of airway inflammation in children with acute asthma using induced sputum. Eur Respir F 1996;9:2104-8.

16 Grootendorst DC, Van Den Bos JW, Rorneijn JJ, et al. Induced sputum in adolescents with severe stable asthma. Safety and the relationship of cell counts and eosinophil cationic protein to clinical severity. Eur Respir f 1999;13: 647-53

17 Gibson PG, Wlodarczyk JW, Hensley MJ, et al. Epidemiological association of airway inflammation with asthma logical association of airway inflammation with asthma symptoms and airway hyperresponsiveness

18 Cai Y, Carty K, Henry RL, Gibson PG. Persistence of sputum eosinophilia in children with controlled asthma when compared with healthy children. Eur Respir f 1998;11:84853.

19 Sanders SP. Nitric oxide in asthma: pathogenic, therapeutic or diagnostic? Am 7 Respir Cell Mol Biol 1999;21:147-9.

20 Baraldi E, Azzolin NM, Zanconato S, Dario C, Zacchello F. Corticosteroids decrease exhaled nitric oxide in children with acute asthma. F Pediatr 1997;131:381-5.

21 Uasuf CG, Jatakanon A, James A, Kharitonov SA, Wilson NM, Barnes PJ. Exhaled carbon monoxide in childhood asthma. F Pediatr 1999;135:569-74.

22 Baraldi E, Dario C, Ongaro R, et al. Exhaled nitric oxide concentrations during treatment of wheezing exacerbation in infants and young children. Am $\mathcal{F}$ Respir Crit Care Med 1999;159:1284-8. 